\title{
A Study on Teaching Strategies of English Writing in Senior High School From the Perspective of Thematic Progression
}

\author{
Zhongiie Fan \\ School of Foreign Languages, Chongqing Normal University, Chongqing, China
}

\begin{abstract}
Writing is an important competence for English learners, which can reflect their English expression ability and logical ability. However, there are still many problems in English writing teaching, such as students' lack of logic and teachers' lack of writing teaching strategies. By analyzing the problems in English writing teaching in senior high school, this study puts forward some pre-writing and post-writing teaching strategies from the perspective of thematic progression, in order to provide more insights for the field of English writing.
\end{abstract}

Index Terms - writing teaching strategies, writing teaching problems, thematic progression

\section{INTRODUCTION}

National English Curriculum Standard for General High School (2017) points out that language competence is an important part of language-using ability. Language competence includes listening, speaking, reading, writing, watching and other competence, among which listening, reading and watching are comprehensive competence while speaking and writing are expressive competence. Through practical English teaching, it is found that writing is the weak competence of most students, which can not be ignored.

In the field of English writing, many scholars have done relevant research. For example, Guo Jia (2021) points out that the difficulty of writing tasks has a significant impact on students' confidence and interests in completing tasks, as well as their motivation to complete similar tasks in the future. This shows that there are a variety of subjective and objective factors affecting students' writing competence in English learning. Teachers should try to overcome the negative factors brought by students' confidence and interests, teach students according to their aptitude, find appropriate writing teaching methods, and help students improve their writing competence. Another example is that students excessively pursue the "economic" principle of language use, resulting in loose discourse structure, monotonous and tedious language (Han Ling, Zhou Ping, 2003). This is an important and common factor leading to students' writing difficulties. Students should realize that writing good English articles requires not only good structure, but also rich language and good textual logic. As can be seen from scholar Tian Lirong (2021), although there are many ways and channels for English learners to learn English, for most English learners, classroom is still the most important place for them to learn language knowledge and develop language competence. To help students improve their writing competence, we need to pay more attention to teaching strategies and methods. Of course, some scholars regard writing as a cyclic and dynamic process by studying the process writing method, and put forward writing teaching strategies such as brainstorming and communication feedback, providing a reference for English writing teaching (Li Jing, 2015). In addition, Huang Ju (2021) conducted a study on thematic progression in high school English writing and found that thematic progression was of great help to the accuracy and fluency of high school English writing.

However, the analysis of the nature of written texts by teachers in these studies is not in-depth enough, and the research on the analysis of writing from the perspective of thematic progression needs to be improved, especially for the high school section. From the perspective of thematic progression, this paper continues to use qualitative research method and sample analysis. The research questions are as follows: 1. What are the problems in English writing teaching in senior high school? 2. How to improve students' writing competence in writing teaching from the perspective of thematic progression? This paper attempts to extend the thematic progression by exploring the linguistic features of the text and the logic of discourse to provide more insights into the field of English writing in senior high school.

\section{BASIC IDEAS OF THEMATIC PROGRESSION}

The two important concepts of functional grammar, theme and rheme, were first proposed by Mathesius, the founder of Prague School, who advocated sentence segmentation according to the actual communicative function of sentences rather than the grammatical function. Mathesius (1939) proposes that the perspective of the functional sentence consists of two communicative units: a Theme, which is known or at least obvious in the given situation, and a Rheme, which represents the speaker's statement. Halliday, an English linguist, helped develop the theory. For the Prague school, the theme is the topic of a sentence, or the object of a sentence narrates. For Halliday, theme is larger than topic, because it includes both topic and other elements at the beginning of a sentence that do not represent topic. Based on this point of view, Halliday 
(1985) proposed the concept of simple theme and multiple themes. He pointed out that the difference between the two is that the former has no internal structure, which cannot be further analyzed, while the latter has internal structure, which can be further divided into textual theme, interpersonal theme and topical theme. Textual theme is related to cohesion of meaning, interpersonal theme describes the communication and relationship between people, including finite, mood, vocative, person and modality, and topical theme mainly refers to the object to be explained in the text. For example, in "When the Prince saw Cinderella", the conjunction "When" has the function of planning discourse, so it belongs to the textural theme. For another example, in "Could we enjoy the paintings together?", "Could" is a modal verb, showing a euphemistic attitude, belonging to the interpersonal theme, and "we" is the topical theme. Although Halliday did not explicitly say that simple theme is a topic theme, the examples he provided in the book all confirmed this point (Zhu Yongsheng, 1995). The introduction of theme and rheme by the scholars above helps people to better understand the discourse, among which, Halliday's three themes will be used to analyze the discourse in this paper.

When it comes to thematic progression, scholar Zhu Yongsheng pointed out that every sentence has its own thematic structure. When a sentence exists alone, its thematic and rheme are determined and will not change. However, when we come into contact with texts, we will find that the vast majority of texts consist of two or more sentences. At this point, there will be some kind of connection and change between theme and theme, theme and rheme, rheme and rheme, and such connection and change is called progression (Zhu Yongsheng, 1995). It can be concluded that there are four modes of thematic progression: theme consistent type, that is, the same theme and different rheme; rheme consistent type, namely, the same rheme, different theme; derived type, which means that the rheme or part of the rheme of the preceding sentence is the theme of the following sentence; split type, in which the theme of the preceding sentence is the rheme of the following sentence.

The above views on theme, rheme and thematic progression are conducive to the in-depth analysis of this paper from the field of English writing teaching, so that high school students can better grasp the rules of discourse, feel the charm of writing and improve their writing competence.

\section{Problems in English Writing Teaching in Senior High School}

\section{A. Psychological Aspect}

On the one hand, students will be afraid of difficulties. High school students, in a relatively mature stage of development, have a strong personality in study and life. In view of the present English writing teaching model, most teachers have the wrong teaching concept of stressing the results and neglecting the process. In the whole process of writing teaching, there is neither preparation before writing, communication between teachers and students, nor repeated feedback and revision, so students are in a passive writing state, and many students think that such English writing is difficult. In addition, students often lack confidence in writing due to a lack of vocabulary and basic writing competence, and they will be afraid of difficulties, which severely dampens their interests in writing (Li Jing, 2015). In addition, writing difficulty, students' self-efficacy and other factors can also affect the writing level. The accuracy of language expression of learners with high self-efficacy in high-complexity writing tasks is not only significantly higher than that of low-complexity writing tasks, but also obviously higher than that of learners with low self-efficacy in high-complexity writing tasks (Yan Rong, Zhang Lei, 2015).

On the other hand, teachers generally do not pay enough attention to English writing teaching. In the context of quality-oriented education, teachers' teaching is still influenced by exam-oriented education, which is manifested in that teachers pay more attention to the teaching of text knowledge, including pronunciation, grammar and vocabulary, while neglecting the cultivation of student' practical English competence.

Whether from the aspect of students' fear or teachers' insufficient attention, the problems existing in the senior high school English writing teaching have a close relation with discourse logic. Hence, teachers need to integrate some advanced ideas including thematic progression into their teaching, in order to help students mentally adapt to writing, better lead students into the field of writing in the process of analyzing articles, and discover more effective ways about writing.

\section{B. Practical Teaching}

First, students lack language foundation and logic. High school students' language knowledge and ability are more perfect than junior high school students, but there is still a lack of vocabulary. Besides, learning at the senior high school is more intense and students study more subjects, which makes them susceptible to a variety of factors when writing, such as their moods and their own thoughts, which can easily result in unclear thoughts and thus affect the logic of their writing.

Second, teachers have not identified effective and innovative strategies for writing teaching. English classes are usually dominated by listening and speaking classes and reading and writing classes. Teachers tend to pay attention to students' knowledge input, namely listening and reading, while tend to ignore students' output, that is, speaking and writing, which affects the formation of students' English competence to a certain extent. In terms of writing, English teachers usually choose boring and direct teaching methods to guide students to write step by step, thus ignoring students' interests and confidence in writing. In addition, students usually do not get timely and appropriate feedback after finishing their writing, which makes it difficult for them to find their own writing problems and analyze their own suitable writing style.

From the above analysis, it can be concluded that in the practical teaching of English writing in senior high school, it is 
necessary to incorporate models or ideas that are beneficial to both discourse analysis and teaching, while thematic progression is not only conducive to the interpretation of discourse, but also provides a good inspiration for the thinking of writing.

\section{Strategies for English Writing Teaching IN SENIOR High SCHOOL}

\section{A. Before Writing}

\section{Help Students Analyze the Text and Identify the Thematic Progression}

Before formal writing, it is suggested that teachers use the text relevant to the content to be written to help students carry out thematic analysis and lay a good writing foundation. When reading a text, we should first help students to distinguish between theme and rheme. The distinction between theme and rheme is that theme is the first element in the clause to express the experiential meaning, whether it refers to participant, process, or circumstance. For example, "Tiffany" means participant, "go, get, walk" means process and "over there" means circumstance. Teachers need to ask questions or explain directly to make students understand what the participants, process and circumstance of the article are, so as to guide students to summarize the content and thematic rules of the article.

Sample analysis:

The following is a sample of text used in the analysis of the writing teaching. It is from a passage in Compulsory 1 published by Chongqing University Press in China. The subtitle of this paragraph is Black Bat Flower:

Black Bat Flower

The black bat flower is an unusual flower that grows in the wild and tropical forests of Yunnan Province in China. It is famous for its bat-shaped black flowers. This flowering plant is often confused with a flying bat. A black bat flower can grow up to 36 inches and be as wide as 12 inches. Every flower has long whiskers which grow up to 28 inches. The flower may also appear in white and brown shades. It needs specific environmental conditions to grow. This is the reason why it is an endangered species.

TABLE 1

THEME AND RHEME

\begin{tabular}{|l|l|l|}
\hline & Topical Theme & Rheme \\
\hline 1 & The black bat flower & $\begin{array}{l}\text { is an unusual flower that grows in the wild and tropical forests of } \\
\text { Yunnan Province in China. }\end{array}$ \\
\hline 2 & It & is famous for its bat-shaped black flowers. \\
\hline 3 & This flowering plant & is often confused with a flying bat. \\
\hline 4 & A black bat flower & can grow up to 36 inches and be as wide as 12 inches. \\
\hline 5 & Every flower & has long whiskers which grow up to 28 inches. \\
\hline 6 & The flower & may also appear in white and brown shades. \\
\hline 7 & It & needs specific environmental conditions to grow. \\
\hline 8 & This & is the reason why it is an endangered species. \\
\hline
\end{tabular}

The above table is about the identification of theme and rheme, which is needed to explain to students by teachers before writing. In this sample, the text consists of eight sentences, which focus on the extraordinary nature of the black bat flower, its state of growth and its endangered environment. As the text is explanatory, it is easy to identify that there are no interpersonal or textual theme and the themes of the eight sentences are all topical. The themes are expressed in different ways, but in essence they are all about the black bat flower, after which we call rheme, including "is an unusual flower that grows in the wild and tropical forests of Yunnan Province in China", "is famous for its bat-shaped black flowers", "is often confused with a flying bat", "can grow up to 36 inches and be as wide as 12 inches", "has long whiskers which grow up to 28 inches", "may also appear in white and brown shades", "needs specific environmental conditions to grow" and "is the reason why it is an endangered species".

After helping the students to identify the theme and rheme, the most important thing for the teacher is to explain how the theme progresses. The theme of the first sentence is "the black bat flower", the word "it" in the second sentence referring to "the black bat flower". The theme of the third sentence is "this flowering plant", after which are "a black bat flower", "every flower", "the flower", "it" and "this". It is worth noting that the theme in the seventh sentence refers to "the black bat flower", but the theme "this" in the eighth sentence refers to the "specific environmental conditions" in the seventh sentence, i.e. the reason for the black bat flower being an endangered species is that it requires a special growing environment. Thus, from the perspective of thematic progression, the text progresses from the theme of the first sentence to the theme of the seventh sentence, and then from the rheme of the seventh sentence to the theme of the last sentence. The above thematic progression enables students to better understand the structure, content of the text and writing ideas, and thus facilitates later writing.

\section{Remind Students of Textual Cohesion and Lexical Chains Based on Thematic Progression}

After understanding the thematic progression, it is suggested for teachers to further analyze the cohesion and lexical chains of the text. Some scholars have found that English sentence logical coherence ability is significantly correlated with English writing level, and cognitive competence of English sentence logical coherence contributes significantly to 
English writing level (Bai Lilu, 2019). Therefore, on the basis of thematic progression, the important task of teachers is to help students further identify themes used in writing and remind students of cohesion and lexical chain use.

Scholars have explained cohesion and lexical chains in detail. Cohesion deals with devices that give a text texture. Cohesive devices include the lexical devices of repetition, semantic relations, equivalence and semblance and the grammatical devices of reference, substitution and ellipsis. Lexical chains are an excellent way of exploring the main preoccupations of speakers and writers and the way their texts develop (Butt, Fahey, Feez, Spinks, Yallop, 2003).

TABLE 2

COHESION

\begin{tabular}{|l|l|l|l|}
\hline & \multicolumn{2}{|l|}{ Lexical device } & Grammatical device \\
\hline & Repetition & Equivalence & Pronominal reference \\
\hline 1 & black bat flower & flower & \\
\hline 2 & & bat-shaped black flowers & it \\
\hline 3 & & this flowering plant & \\
\hline 4 & & every flower & this \\
\hline 5 & black bat flower & the flower & \\
\hline 6 & & & it \\
\hline 7 & & & this, it \\
\hline 8 & & & \\
\hline
\end{tabular}

TABLE 3

LEXICAL CHAINS

\begin{tabular}{|l|l|l|}
\hline & Chain 1: Flower & Chain 2: Length \\
\hline 1 & flower & \\
\hline 2 & flower & \\
\hline 3 & flower & \\
\hline 4 & flower & inches, inches \\
\hline 5 & flower & inches \\
\hline 6 & flower & \\
\hline 7 & flower & \\
\hline 8 & flower & \\
\hline
\end{tabular}

Similarly, teachers can use a table to illustrate the text from the perspectives of cohesion and lexical chains. In the aspect of cohesion, the only lexical devices are repetition ("black bat flower" in the first and fourth sentences) and equivalence ("flower", "bat-shaped black flowers", "this flowering plant", "every flower" and "the flower"), and the only grammatical device in this sample is pronominal reference, including "it" and "this". In terms of lexical chains, the text can be divided into two lexical chains, one for flower and one for the length of growth of flower, which are relatively easy to summarize.

\section{B. After Writing}

\section{Work in Groups to Examine and Reflect on the Use of Thematic Progression}

Research shows that the interaction mode formed in students' cooperative writing can have a certain impact on the results of second language learning (Deng Yuan, Niu Ruiying, Deng Hua, 2021). Therefore, it is essential for English teachers to guide students through a collaborative group check after students finish their writing, not only to help students refine the content of their compositions, but also in turn to facilitate the teacher's writing teaching. To be specific, students in a group exchange with each other, check whether there are any mistakes in the use of themes of other students, discuss other themes that may appear, analyze how the thematic progression of students' compositions is made, and finally learn from each other, so as to write a more perfect composition next time.

\section{Invite Students to Present Their Compositions from a Thematic Progression Perspective}

Teachers should be aware of the important roles of thematic progression for students before and after writing. Thematic progression not only helps students to clarify their ideas and build a foundation before writing, but also serves as a way or criterion for students to reflect on the clarity, logic and focus of their ideas in their essays after writing. Although there are different genres of essays, including expository essays, argumentative essays, narrative essays and so on, the use of thematic progression in writing can largely help students to identify the main points that need to be expressed and to clarify their ideas so that the quality of their essays can be improved.

On the basis of this sample, the following reference is given for writing a summary with the help of thematic progression: The black bat flower is an unusual flower for its confusing bat-shaped black flowers, can grow up to 36 inches long and 12 inches wide, has 28-inch long whiskers, may appear in white and brown shades and becomes an endangered species due to its need for specific environmental conditions.

This version is based on the knowledge of thematic progression, cohesion and lexical chains, first finding out the theme of each sentence and the rheme from the original text, focusing on grasping the content of the rheme, thus analyzing how the themes progress, and then integrating thematic progression with the language cohesion and coherence, finally discovering the key content and writing logic of the text. In the formal writing of the summary, the extraordinary nature, length of growth and endangered environment of the black bat flower were highlighted, with attention to concise, logical 
and focused language.

Therefore, another teaching strategy of the teacher after writing is to invite students to share the composition from the thematic progression perspective to the whole class, so as to achieve the effect of collective thinking.

\section{CONCLUSION}

This paper attempts to answer the existing problems of English writing in senior high school from the perspective of thematic progression and what writing teaching strategies should be used by teachers. On the one hand, the current problems in writing teaching are mainly psychological and pedagogical, and the reasons for the psychological aspects of both teachers and students are closely related to the logic of the text, etc., which shows that the use of thematic progression needs to be brought to attention. On the other hand, in teaching strategies, teachers can divide writing instruction into pre-writing and post-writing, help students to analyze thematic progression and interpret cohesion and lexical chains before writing, and lead students to cooperate in groups, check and share compositions from the perspective of thematic progression after writing, so as to improve students' writing competence. However, different writing teaching concepts have different applicable conditions, for example, in the perspective of process writing concept teachers need to inspire students' problem consciousness and to give students sufficient time to write (Fang $\mathrm{xu}, 2011$ ). Likewise, there are conditions under which this paper is applicable, namely that the more logical students may be more likely to master the thematic progression. This is where the paper falls short and we will be refined in the future in the hope of providing further insights into the field of writing.

\section{REFERENCES}

[1] Bai Liru. (2019). A Study on the Potential Relationship between English Sentence Coherence Ability and English Writing Level, Foreign Languages Research, 1, 52-57.

[2] David Butt, Rhondda Fahey, Susan Feez, Sue Spinks, Colin Yallop. (2003). Using Functional Grammar-An Explorer's Guide, National Centre for English Language Teaching and Research, 136-149.

[3] Deng Yuan, Niu Ying, Deng Hua. (2021). A Study of the Effects of Different Level Allocations in Collaborative Writing on Learners' Second Language Learning. Foreign Languages Research, 1, 62-68.

[4] Guo jia, Zhang Dan, Cui Sihan, Zhao Linying. (2021). An Empirical Study of Two-way Vectors of Task Complexity and Task Difficulty in Chinese Students' English Writing Output, Foreign Languages Research, 3, 66-72.

[5] Halliday, M.A.K. (1985). An Introduction to Functional Grammar. London: Edward Arnold.

[6] Han Ling, Zhou Ping. (2003). An Analysis of the Illocutionary Bias in Chinese Students' English Writing, Foreign Languages Research, 2, 70-73.

[7] Huang Ju. (2021). A Case Study on the Application of Thematic Progression Model in English Writing Teaching in Senior High School, Jilin University of Foreign Studies, 2-8.

[8] Li Jing. (2015). A study on the Teaching Strategies of Process Writing Method in Senior High School, Foreign Language Teaching in Schools, 11, 23-26.

[9] Mathesius, V. (1939). Functional Sentence Perspective. Prague: Academia.

[10] Ministry of Education of the People's Republic of China. (2017). National English Curriculum Standard for General High School, People's Education Press, 35-39.

[11] Tian Lirong. (2021). A Study on What English Teachers Should Do in the English Classroom, Theory and Practice in Language Studies, 7, 858-863.

[12] Xu Fang. (2011). A Theoretical Review and Reflection on the Multiple Perspectives of English Writing Pedagogy, Foreign Language World, 2, 57-64.

[13] Yan Rong, Zhang Lei. (2015). The Effects of Task Complexity, Task Difficulty and Self-efficacy on Foreign Language Writing, Foreign Language World, 1, 40-47.

[14] Zhu Yongsheng. (1995). Thematic Progression and Discourse Analysis, Foreign Language Teaching and Research, 3, 6-11.

Zhongjie Fan was born in Chongqing, China in 1998. She is now a postgraduate in the School of Foreign Languages, Chongqing Normal University, Chongqing, China. Her research interests include foreign language teaching and linguistics. 